\title{
Association between Serum Dipeptidyl Peptidase-4 Concentration and Obesity-related Factors in Health Screen Examinees
}

\author{
Ji Yeon Lee', Byoung Kuk Jang 1,2, Min Kyung Song ${ }^{3}$, Hye Soon Kim', Mi-Kyung Kim ${ }^{1, *}$ \\ 'Department of Internal Medicine, Keimyung University School of Medicine, Daegu; ${ }^{2}$ Institute for Cancer Research, Keimyung University, Daegu; ${ }^{3}$ Department of \\ Food Science and Nutrition, Graduate School, Keimyung University, Daegu, Korea
}

Background: Dipeptidyl peptidase-4 (DPP-4) is an aminopeptidase that inhibits the enzymatic degradation of glucagon-like peptide-1, glucose-dependent insulinotropic polypeptides, neuropeptides, and various chemokines. Recent studies reported that serum DPP-4 concentration is correlated with clinical parameters of obesity. However, research on these correlations has never been conducted in Korea. Therefore, we investigated the relationship between serum DPP-4 concentration and various clinical parameters of obesity in the Korean population. Methods: Patients who visited the Health Promotion Center at Keimyung University Dongsan Medical Center for a regular medical examination between January 2013 and March 2013 and consented to participate in this study were included. We measured and analyzed parameters of obesity. In addition, serum DPP-4 concentration was determined using an enzyme-linked immunosorbent assay kit.

Results: Serum DPP-4 concentration was positively correlated with lean body mass, total cholesterol level, and creatinine level. Serum DPP-4 concentration was higher in the obese group than in the normal body mass index (BMI) group. No significant difference in serum DPP-4 concentration was found between the metabolically healthy group and metabolically unhealthy group.

Conclusion: Serum DPP-4 concentration was higher in the obesity group than in the normal BMI group, which was associated with obesity-related factors.

Key words: Dipeptidyl peptidase-4, Obesity, Biomarker
Received August 18, 2016

Reviewed September 20, 2016

Accepted April 19, 2017

*Corresponding author

Mi-Kyung Kim

(iD)

http://orcid.org/0000-0001-5750-3598

Department of Internal Medicine, Keimyung University School of Medicine, 56 Dalseong-ro, Jung-gu, Daegu 41931, Korea

Tel: $+82-53-250-7486$

Fax: +82-53-250-7982

E-mail:mdkmk@dsmc.or.kr

\section{INTRODUCTION}

Obesity, one of the typical characteristics of metabolic syndrome, is recognized as a major health problem and is associated with insulin resistance, diabetes, atherosclerosis, hypertension, chronic renal insufficiency, and cardiovascular diseases worldwide. ${ }^{1}$ The World Health Organization (WHO) has reported that there are more than 600 million obese adults worldwide ${ }^{2}$, and the National Health and Nutrition Examination Survey (2010) conduct- ed in the United States has reported that people aged 20 years or older account for $35.7 \%$ of the entire obese population with body mass index (BMI) greater than or equal to $30 \mathrm{~kg} / \mathrm{m}^{2}{ }^{2}$ According to the Korea National Health and Nutrition Examination Survey (2012), the prevalence rate of obesity (defined as BMI $\geq 25 \%$ ) was $32.8 \%$ among Korean adults, which was higher among men than women. ${ }^{4}$ Adipose tissue, which had previously only been understood to store excess energy, was acknowledged as a major endocrine organ following the discovery of leptin in $1994{ }^{5,6}$ Various adi-

Copyright (C) 2017 Korean Society for the Study of Obesity

(c) This is an Open Access article distributed under the terms of the Creative Commons Attribution Non-Commercial License (http://creativecommons.org/licenses/by-nc/4.0/) which permits unrestricted non-commercial use, distribution, and reproduction in any medium, provided the original work is properly cited. 
pokines released by adipose cells such as leptin and adiponectin regulate lipid metabolism, energy homeostasis, and insulin resistance; thereby, affecting the development of metabolic syndrome associated with obesity. ${ }^{5,6}$ By understanding the changes in adipokine levels, metabolic dysregulation may be predicted, and a considerable amount of research has been conducted in this regard.

Dipeptidyl peptidase-4 (DPP-4), a serine protease, degrades peptides containing alanine or proline residues and amino-terminal residues of proteins. ${ }^{7}$ DPP-4 is an aminopeptidase found in most tissues of the body, including the liver, lung, kidney, intestine, lymph nodes, and endothelial cells, and resides on cell membranes where it exerts its effect. Physiological effects of DPP-4 can be broadly divided into enzymatic effects and non-enzymatic effects. A major example of the enzymatic effects of DPP-4 is the inhibition of incretins such as glucagon-like peptide-1 (GLP-1) and glucose-dependent insulinotropic peptide. Therefore, inhibiting DPP4 activates incretin effects, and lowers blood glucose levels. For this reason, DPP-4 inhibitors have been widely used as antihyperglycemic drugs. ${ }^{8,9}$ Non-enzymatic effects of DPP-4 are reported to be associated with immune regulation, behavioral response, and inflammation depending on the substance on which DPP- 4 acts. ${ }^{10}$ In previous studies, DPP-4 activity was associated with obesity, diabetes, and fatty liver, serum DPP-4 concentration increased as the size of adipose cells increased, and serum DPP-4 concentration was higher in obese people than in underweight people. ${ }^{11-14}$ Based on all these results, serum DPP-4 is considered a new obesity-related factor. However, there has not been any research on the correlation between DPP-4 concentration and obesity in the Korean population. The goals of this study were to measure the serum DPP-4 concentration in Korean participants undergoing routine medical examination and to investigate the association of serum DPP-4 concentration with obesity-related factors, including adiponectin.

\section{METHODS}

\section{Participants and methods}

A total of 594 patients, who had a medical examination performed at the Health Promotion Center of Keimyung University Dongsan Medical Center during the period from January 2013 to March 2013 and consented to participate in this study, were includ- ed. Of these patients, those with hypertension, diabetes, and dyslipidemia were excluded, and the remaining 452 healthy adults were finally selected. The patients' age and sex were investigated, and obesity-related factors were measured through a physical examination, body composition test, and blood test. The patients' height $(\mathrm{cm})$ and weight $(\mathrm{kg})$ were measured to the nearest tenth, using an automatic height and weight machine (DS-102 model, Dong Sahn Jenix Co., Ltd, Seoul, Korea), while the patients were wearing a hospital gown. The patients were classified as normal weight (BMI $\left.<23 \mathrm{~kg} / \mathrm{m}^{2}\right)$, overweight $\left(23 \mathrm{~kg} / \mathrm{m}^{2} \leq \mathrm{BMI}<25 \mathrm{~kg} / \mathrm{m}^{2}\right)$, and obese (BMI $\geq 25 \mathrm{~kg} / \mathrm{m}^{2}$ ) based on their BMI. ${ }^{15}$ BMI was calculated by dividing weight $(\mathrm{kg})$ by the square of height $(\mathrm{m})\left(\mathrm{kg} / \mathrm{m}^{2}\right)$. Blood pressure was measured with a standard sphygmomanometer after the patients rested for 5 minutes. Body composition was measured using bioelectric impedance analysis according to the manufacturer's instructions (Inbody 720, Biospace, Seoul, Korea), and an abdominal ultrasound was performed to check for the presence of fat infiltration in the liver (fatty liver disease). All tests were performed while the patients were in the fasting state. Fasting glucose levels were measured by an enzyme-amperometric method using a ChipSensor (EKF Diagnostic, Wales, UK), and fasting insulin levels were measured by using a radioimmunoassay (Beckman Instruments Inc., CA, USA). An enzyme-linked immunosorbent assay was used to measure serum concentration of DPP-4 (R\&D, Minneapolis, MN, USA), leptin (R\&D, Minneapolis, MN, USA), and adiponectin (R\&D, Minneapolis, MN, USA). Homeostasis model assessment-insulin resistance (HOMA-IR) was used as a marker of insulin resistance and calculated by the following equation: fasting glucose level $(\mathrm{mg} / \mathrm{dL}) \times$ insulin $(\mu \mathrm{IU} / \mathrm{mL}) /(18 \times 22.5)$.

The obesity group was further divided into metabolically healthy and metabolically unhealthy groups, for comparison. The patients were classified as metabolically unhealthy obese (MUHO) if they satisfied two or more of the following conditions: (1) systolic pressure $\geq 130 \mathrm{mmHg}$, diastolic pressure $\geq 85 \mathrm{mmHg}$, or currently taking antihypertensive medications; (2) triglyceride level $\geq 150$ $\mathrm{mg} / \mathrm{dL}$; (3) fasting glucose level $\geq 100 \mathrm{mg} / \mathrm{dL}$; (4) high-density lipoprotein (HDL) $<40 \mathrm{mg} / \mathrm{dL}$ for men, and $<50 \mathrm{mg} / \mathrm{dL}$ for women; and (5) HOMA-IR in the 90th percentile or higher. Patients who satisfied less than two of the aforementioned conditions were classified as metabolically healthy obese (MHO) ${ }^{16}$ This study 
was approved by the Institutional Review Board (IRB) of Keimyung University Dongsan Medical Center (IRB No. 12-221).

\section{Statistical analysis}

All statistical analyses were performed using Statistical Package for the Social Sciences (SPSS) software, version 23.0 (IBM Corp., Armonk, NY, USA). The continuous variables of the general characteristics were expressed as means and standard deviations, and the nominal variables were expressed as numbers and percentages. For continuous variables with a normal distribution, a $t$-test and oneway analysis of variance were performed. For comparison of continuous variables without a normal distribution, a Mann-Whitney test and Kruskal-Wallis test were used. To study the association between serum DPP-4 concentration and obesity-related factors, a Pearson correlation analysis was performed. Serum DPP-4 concentration was log-transformed because the data were not normally distributed. A multiple regression analysis was performed to identify factors that are independently associated with serum DPP-4 concentration. The $95 \%$ confidence interval was estimated based on a binomial distribution. The level of statistical significance was set at a $P<0.05$.

\section{RESULTS}

\section{General characteristics of the participants}

The mean age of all participants was $42.58 \pm 9.70$ years. The participants consisted of 188 men (41.6\%), and 264 women (58.4\%). The mean BMI was $23.15 \pm 3.12 \mathrm{~kg} / \mathrm{m}^{2}$, the mean body fat percentage was $27.95 \% \pm 6.18 \%$, the mean systolic pressure was $118.68 \pm 14.21 \mathrm{mmHg}$, the mean diastolic pressure was $74.00 \pm$ $9.86 \mathrm{mmHg}$, the mean total cholesterol level was $188.41 \pm 33.27$ $\mathrm{mg} / \mathrm{dL}$, the mean triglyceride level was $103.96 \pm 74.60 \mathrm{mg} / \mathrm{dL}$, the mean HDL level was $52.35 \pm 10.90 \mathrm{mg} / \mathrm{dL}$, the mean low-density lipoprotein (LDL) level was $156.85 \pm 42.17 \mathrm{mg} / \mathrm{dL}$, the mean fasting glucose level was $84.95 \pm 12.74 \mathrm{mg} / \mathrm{dL}$, the mean insulin level was $4.10 \pm 2.64 \mu \mathrm{IU} / \mathrm{mL}$, the mean HOMA-IR was $0.90 \pm 0.80$, and the mean serum log DPP- 4 concentration was $2.69 \pm 0.11 \mathrm{ng} /$ $\mathrm{mL}$. The mean adiponectin level was $5.64 \pm 4.06 \mu \mathrm{g} / \mathrm{mL}$, and the mean leptin level was $2.08 \pm 1.71 \mathrm{ng} / \mathrm{mL}$. Fatty liver was observed in 111 subjects $(24.6 \%)$ (Table 1$)$.
Table 1. General characteristics of the participants

\begin{tabular}{|c|c|}
\hline Characteristics & Total $(n=452)$ \\
\hline Age (yr) & $42.58 \pm 9.70$ \\
\hline Sex (male/female) & $188(41.6 \%) / 264(58.4 \%)$ \\
\hline Body weight (kg) & $63.31 \pm 12.07$ \\
\hline Body mass index $\left(\mathrm{kg} / \mathrm{m}^{2}\right)$ & $23.15 \pm 3.12$ \\
\hline Waist circumference (cm) & $81.90 \pm 8.90$ \\
\hline Hip circumference (cm) & $92.87 \pm 6.99$ \\
\hline Waist hip ratio & $0.88 \pm 0.05$ \\
\hline Lean body mass (kg) & $45.60 \pm 9.71$ \\
\hline Fat mass (kg) & $17.71 \pm 5.45$ \\
\hline Body fat percentage (\%) & $27.95 \pm 6.18$ \\
\hline Systolic blood pressure (mmHg) & $118.68 \pm 14.21$ \\
\hline Diastolic blood pressure (mmHg) & $74.00 \pm 9.86$ \\
\hline Total cholesterol (mg/dL) & $188.41 \pm 33.27$ \\
\hline Triglyceride (mg/dL) & $103.96 \pm 74.60$ \\
\hline HDL cholesterol (mg/dL) & $52.35 \pm 10.90$ \\
\hline LDL cholesterol (mg/dL) & $156.85 \pm 42.17$ \\
\hline AST (IU/L) & $22.74 \pm 12.18$ \\
\hline ALT (IU/L) & $22.77 \pm 18.25$ \\
\hline Fasting glucose (mg/dL) & $84.95 \pm 12.74$ \\
\hline Insulin ( $\mu \mid \mathrm{U} / \mathrm{mL})$ & $4.10 \pm 2.64$ \\
\hline HOMA-IR & $0.90 \pm 0.80$ \\
\hline Adiponectin ( $\mu \mathrm{g} / \mathrm{mL})$ & $5.64 \pm 4.06$ \\
\hline Leptin (ng/mL) & $2.08 \pm 1.71$ \\
\hline DPP-4 concentration (ng/mL) & $501.27 \pm 125.94$ \\
\hline Log DPP-4 concentration (ng/mL) & $2.69 \pm 0.11$ \\
\hline Fatty liver $(n, \%)$ & $111(24.6)$ \\
\hline
\end{tabular}

Values are normal distribution and are presented as mean \pm SD or number $(\%)$. HDL, high density lipoprotein; LDL, low density lipoprotein; AST, aspartate transaminase; ALT, alanine transaminase; HOMA-IR, homeostasis model assessment of insulin resistance; DPP-4, dipeptidyl peptidase-4.

\section{Correlation between serum DPP-4 concentration and obesity-related factors in all groups}

We analyzed the correlations between serum DPP-4 concentration and obesity-related factors in all groups. Serum DPP-4 concentration was significantly positively correlated with body weight, BMI, lean body mass, waist circumference, hip circumference, waist-to-hip ratio (WHR), blood pressure, total cholesterol, triglyceride, LDL, blood urea nitrogen (BUN), and creatinine, and significantly negatively correlated with body fat percentage and adiponectin (Table 2, Fig. 1). A multivariate analysis of body mass, BMI, waist circumference, hip circumference, WHR, lean body mass, body fat percentage, LDL, triglyceride, total cholesterol, blood pressure, BUN, creatinine, and adiponectin (all of which were 
Table 2. Bivariate correlation analyses of metabolic parameters and DPP-4 concentration*

\begin{tabular}{|c|c|c|}
\hline & $r$ & $P$ \\
\hline Body weight (kg) & 0.227 & $<0.001$ \\
\hline Body mass index $\left(\mathrm{kg} / \mathrm{m}^{2}\right)$ & 0.133 & 0.005 \\
\hline Waist circumference $(\mathrm{cm})$ & 0.139 & 0.003 \\
\hline Hip circumference (cm) & 0.098 & 0.037 \\
\hline Waist hip ratio & 0.144 & 0.002 \\
\hline Lean body mass $(\mathrm{kg})$ & 0.263 & $<0.001$ \\
\hline Fat mass (kg) & 0.027 & 0.563 \\
\hline Body fat percentage $(\%)$ & -0.141 & 0.003 \\
\hline Systolic blood pressure (mmHg) & 0.186 & $<0.001$ \\
\hline Diastolic blood pressure (mmHg) & 0.176 & $<0.001$ \\
\hline Total cholesterol (mg/dL) & 0.223 & $<0.001$ \\
\hline Triglyceride (mg/dL) & 0.129 & 0.006 \\
\hline HDL cholesterol (mg/dL) & 0.006 & 0.899 \\
\hline LDL cholesterol (mg/dL) & 0.220 & $<0.001$ \\
\hline Fasting glucose (mg/dL) & 0.074 & 0.117 \\
\hline Insulin ( $\mu \mid \mathrm{U} / \mathrm{mL})$ & 0.049 & 0.296 \\
\hline HOMA-IR & 0.058 & 0.217 \\
\hline $\mathrm{CRP}(\mathrm{mg} / \mathrm{dL})$ & -0.001 & 0.983 \\
\hline BUN (mg/dL) & 0.149 & 0.020 \\
\hline Creatinine (mg/dL) & 0.273 & $<0.001$ \\
\hline Leptin (ng/mL) & -0.074 & 0.118 \\
\hline Adiponectin $(\mu \mathrm{g} / \mathrm{mL})$ & -0.096 & 0.042 \\
\hline
\end{tabular}

Correlation coefficients(r) and unadjusted $P$-values are calculated by Pearson correlation model.

* Log transformed values were used for analysis.

DPP-4, dipeptidyl peptidase-4; HDL, high density lipoprotein; LDL, low density lipoprotein; HOMA-IR, homeostasis model assessment of insulin resistance; CRP, C-reactive protein; BUN, blood urea nitrogen.

found to be significantly associated with serum DPP-4 concentration in the correlation analysis) showed that serum DPP-4 concentration was significantly positively correlated with lean body mass, total cholesterol, and creatinine (Table 3).

\section{Comparison of serum DPP-4 concentration by BMI and obesity type}

Since a correlation was found between serum DPP-4 concentration and BMI, serum DPP-4 concentration was compared among the normal weight $\left(B M I<23 \mathrm{~kg} / \mathrm{m}^{2}\right)$, overweight $\left(23 \mathrm{~kg} / \mathrm{m}^{2} \leq\right.$ $\left.\mathrm{BMI}<25 \mathrm{~kg} / \mathrm{m}^{2}\right)$, and obese $\left(\mathrm{BMI} \geq 25 \mathrm{~kg} / \mathrm{m}^{2}\right)$ subjects. As BMI increased, measurements of the obesity-related factors, including body fat percentage, and the risk for dyslipidemia increased, and serum DPP-4 concentration also increased (Table 4). No significant difference in serum DPP-4 concentration was found between the

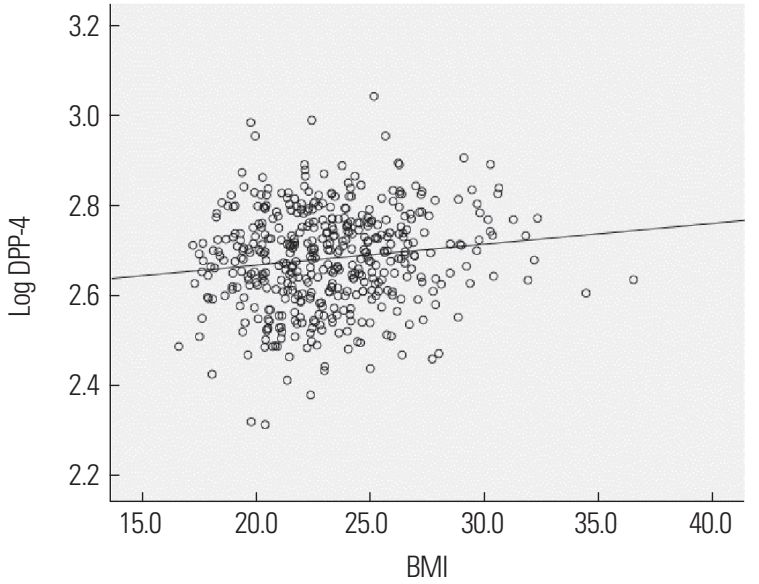

Figure 1. Correlation between serum dipeptidyl peptidase-4 (DPP-4) concentration and body mass index (BMI).

Table 3. Multivariable analysis examining for independent association of metabolic parameters with DPP-4 concentration* by linear regression

\begin{tabular}{lccc}
\hline & $\beta \pm S E$ & Partial $\mathrm{R}^{2}$ & $P$ \\
\hline Lean body mass $(\mathrm{kg})$ & $0.0015 \pm 0.0006$ & 0.0102 & 0.0319 \\
Creatinine $(\mathrm{mg} / \mathrm{dL})$ & $0.1016 \pm 0.0338$ & 0.0151 & 0.0092 \\
Total cholesterol $(\mathrm{mg} / \mathrm{dL})$ & $0.0005 \pm 0.0001$ & 0.0323 & 0.0001 \\
\hline
\end{tabular}

* Log-transformed values were used for analysis.

DPP-4, dipeptidyl peptidase-4; SE, standard errors.

overweight group and obese group in the post hoc analysis, while a significant difference in serum DPP-4 concentration was found between the normal weight group and obese group.

A comparison of the $\mathrm{MHO}$ and $\mathrm{MUHO}$ groups showed higher BMI, blood pressure, triglyceride, fasting glucose, insulin levels, and HOMA-IR, and proportion of participants with fatty liver, and a lower HDL level in the MUHO group than in the MHO group. However, no significant difference in serum log DPP-4 concentration was found between the MHO and MUHO groups (2.71 \pm 0.11 , and $2.72 \pm 0.09$, respectively) $(P=0.592)$. Thus, no significant difference in serum DPP-4 concentration was found according to obesity type (Table 5).

\section{DISCUSSION}

In this study, serum DPP-4 concentration was found to be positively correlated with lean body mass, total cholesterol, and creatinine. Serum DPP-4 concentration was also elevated in the obese group compared to the normal weight group. 
Table 4. Comparison of characteristics and metabolic parameters according to body mass index

\begin{tabular}{|c|c|c|c|c|}
\hline & Normal $(\mathrm{BMI}<23)(\mathrm{n}=235)$ & Overweight $(23 \leq \mathrm{BMl}<25)(\mathrm{n}=102)$ & Obese $(B M I \geq 25)(n=115)$ & $P$ \\
\hline Age (yr) & $40.45 \pm 9.33$ & $45.25 \pm 8.85$ & $44.57 \pm 10.21$ & $<0.001$ \\
\hline Sex, male & $57(24.3 \%)$ & $53(52.0 \%)$ & $78(67.8 \%)$ & $<0.001$ \\
\hline Sex, female & $178(75.7 \%)$ & $49(48.0 \%)$ & $37(32.2 \%)$ & $<0.001$ \\
\hline Body weight (kg) & $55.71 \pm 6.36$ & $64.75 \pm 6.42$ & $77.55 \pm 11.45$ & $<0.001$ \\
\hline Body mass index $\left(\mathrm{kg} / \mathrm{m}^{2}\right)$ & $20.78 \pm 1.49$ & $23.98 \pm 0.58$ & $27.27 \pm 2.11$ & $<0.001$ \\
\hline Waist circumference $(\mathrm{cm})$ & $75.73 \pm 5.13$ & $84.89 \pm 4.73$ & $91.85 \pm 7.30$ & $<0.001$ \\
\hline Hip circumference (cm) & $88.89 \pm 4.70$ & $94.26 \pm 4.58$ & $99.77 \pm 6.84$ & $<0.001$ \\
\hline Waist hip ratio & $0.85 \pm 0.04$ & $0.90 \pm 0.03$ & $0.92 \pm 0.04$ & $<0.001$ \\
\hline Lean body mass (kg) & $41.04 \pm 6.32$ & $45.98 \pm 8.18$ & $54.56 \pm 10.38$ & $<0.001$ \\
\hline Fat mass $(\mathrm{kg})$ & $14.67 \pm 3.30$ & $18.77 \pm 3.90$ & $22.99 \pm 5.78$ & $<0.001$ \\
\hline Body fat percentage $(\%)$ & $26.38 \pm 5.53$ & $29.07 \pm 6.27$ & $30.17 \pm 6.49$ & $<0.001$ \\
\hline Systolic blood pressure (mmHg) & $113.40 \pm 12.06$ & $121.64 \pm 14.45$ & $126.86 \pm 13.47$ & $<0.001$ \\
\hline Diastolic blood pressure (mmHg) & $70.87 \pm 8.51$ & $75.71 \pm 10.39$ & $78.88 \pm 9.68$ & $<0.001$ \\
\hline Total cholesterol (mg/dL) & $182.34 \pm 31.73$ & $191.18 \pm 33.14$ & $198.38 \pm 34.00$ & $<0.001$ \\
\hline Triglyceride (mg/dL) & $80.33 \pm 45.36$ & $114.40 \pm 66.77$ & $143.01 \pm 105.14$ & $<0.001$ \\
\hline HDL cholesterol (mg/dL) & $55.84 \pm 11.03$ & $49.79 \pm 10.21$ & $47.51 \pm 8.55$ & $<0.001$ \\
\hline LDL cholesterol (mg/dL) & $142.56 \pm 36.17$ & $164.27 \pm 36.95$ & $179.48 \pm 46.41$ & $<0.001$ \\
\hline Fasting glucose (mg/dL) & $81.78 \pm 7.77$ & $85.87 \pm 12.33$ & $90.59 \pm 18.16$ & $<0.001$ \\
\hline Insulin ( $\mu \mid \mathrm{U} / \mathrm{mL})$ & $3.37 \pm 1.98$ & $4.09 \pm 2.28$ & $5.60 \pm 3.40$ & $<0.001$ \\
\hline HOMA-IR & $0.69 \pm 0.46$ & $0.88 \pm 0.54$ & $1.32 \pm 1.26$ & $<0.001$ \\
\hline Leptin (ng/mL) & $1.87 \pm 1.42$ & $2.25 \pm 1.93$ & $2.34 \pm 1.98$ & 0.101 \\
\hline Adiponectin $(\mu \mathrm{g} / \mathrm{mL})$ & $6.49 \pm 4.49$ & $5.06 \pm 3.03$ & $4.42 \pm 3.51$ & $<0.001$ \\
\hline Log DPP-4 concentration (ng/mL) & $2.67 \pm 0.12$ & $2.69 \pm 0.10$ & $2.71 \pm 0.10$ & 0.009 \\
\hline Fatty liver & $26(11.1 \%)$ & $30(29.4 \%)$ & $55(47.8 \%)$ & $<0.001$ \\
\hline
\end{tabular}

Values are normal distribution and are presented as mean \pm standard deviation (SD) or number (\%).

One way analysis of variance or chi-square test or Kruskal-Wallis test.

BMI, body mass index; HDL, high-density lipoprotein; LDL, low-density lipoprotein; HOMA-IR, homeostasis model assessment of insulin resistance; DPP-4, dipeptidyl peptidase-4.

DPP-4 is an aminopeptidase found in most tissues of the body, including the liver, lungs, kidneys, intestinal tract, lymph nodes, and epithelial cells, and resides on the cell membrane of T cells, B cells, and natural killer cells to exert its effect. ${ }^{17,18}$ DPP-4 is known to play a role in the immune response and degradation of incretin hormones and has been recently reported to be associated with obesity. Kirino et al. ${ }^{13}$ reported that serum DPP-4 activity is positively correlated with BMI and total cholesterol and negatively correlated with adiponectin in healthy young adults without underlying diseases. Firneisz et al. ${ }^{11}$ reported increased serum DPP-4 activity and HOMA-IR in patients with non-alcoholic fatty liver disease compared to patients without fatty liver disease. These results have suggested that the level of DPP-4 activity may be used as a predictor of obesity and metabolic syndrome. It has also been reported that the progress and prognosis of non-alcoholic fatty liver disease can be predicted by measuring the activity of circulating DPP-4, and liver histology can be improved by inhibiting DPP-4 activity. ${ }^{19}$ Lamers et al. ${ }^{14}$ observed the upregulation of DPP-4 in differentiated adipose tissue and disruption in insulin signaling pathways upon adding DPP-4 to adipose and muscle cells. In addition, DPP-4 expression was higher in subcutaneous fat than in visceral fat in obese patients and positively correlated with the degree of obesity and markers of metabolic syndrome. These findings suggest that DPP4 may be a new adipokine that can increase insulin resistance. ${ }^{14}$ In the present study, serum DPP-4 concentration was found to increase as BMI, WHR, blood pressure, and total cholesterol, triglyceride, and LDL levels increased, and to be negatively correlated with adiponectin. While the same correlations were observed for serum DPP-4 concentration with BMI, waist circumference and adiponectin in a study by Lamers et al. ${ }^{14}$, no significant change in serum DPP-4 concentration was observed according to leptin and insulin levels in our study. We also found that serum DPP-4 con- 
Table 5. Comparison of characteristics and metabolic parameters according to obesity status

\begin{tabular}{|c|c|c|c|}
\hline & $\mathrm{MHO}(\mathrm{n}=77)$ & $\mathrm{MUHO}(\mathrm{n}=38)$ & $P^{*}$ \\
\hline Age (yr) & $43.82 \pm 9.81$ & $46.11 \pm 10.96$ & 0.326 \\
\hline Sex, male & $48(62.3 \%)$ & $30(78.9 \%)$ & 0.073 \\
\hline Sex, female & $29(37.7 \%)$ & $8(21.1 \%)$ & 0.073 \\
\hline Body weight (kg) & $76.01 \pm 11.24$ & $80.68 \pm 11.37$ & 0.039 \\
\hline Body mass index $\left(\mathrm{kg} / \mathrm{m}^{2}\right)$ & $26.90 \pm 1.95$ & $28.00 \pm 2.27$ & 0.003 \\
\hline Waist circumference $(\mathrm{cm})$ & $91.55 \pm 6.24$ & $92.44 \pm 9.14$ & 0.136 \\
\hline Hip circumference (cm) & $99.76 \pm 6.45$ & $99.79 \pm 7.66$ & 0.98 \\
\hline Waist hip ratio & $0.92 \pm 0.03$ & $0.93 \pm 0.04$ & 0.205 \\
\hline Lean body mass $(\mathrm{kg})$ & $53.14 \pm 10.56$ & $57.44 \pm 9.51$ & 0.036 \\
\hline Fat mass (kg) & $22.87 \pm 5.39$ & $23.24 \pm 6.57$ & 0.730 \\
\hline Body fat percentage $(\%)$ & $30.41 \pm 6.72$ & $29.69 \pm 6.07$ & 0.579 \\
\hline Systolic blood pressure (mmHg) & $123.47 \pm 12.95$ & $133.74 \pm 11.92$ & $<0.001$ \\
\hline Diastolic blood pressure (mmHg) & $76.31 \pm 8.50$ & $84.08 \pm 9.93$ & $<0.001$ \\
\hline Total cholesterol (mg/dL) & $195.22 \pm 33.14$ & $204.79 \pm 35.25$ & 0.157 \\
\hline Triglyceride (mg/dL) & $99.65 \pm 38.96$ & $230.85 \pm 138.21$ & $<0.001$ \\
\hline HDL cholesterol (mg/dL) & $49.54 \pm 8.51$ & $43.38 \pm 7.11$ & $<0.001$ \\
\hline LDL cholesterol (mg/dL) & $165.61 \pm 36.20$ & $207.58 \pm 52.27$ & $<0.001$ \\
\hline Fasting glucose (mg/dL) & $85.95 \pm 10.06$ & $100.00 \pm 25.92$ & $<0.001$ \\
\hline Insulin ( $\mu \mid \mathrm{U} / \mathrm{mL})$ & $4.37 \pm 1.81$ & $8.08 \pm 4.40$ & $<0.001$ \\
\hline HOMA-IR & $0.93 \pm 0.42$ & $2.11 \pm 1.90$ & $<0.001$ \\
\hline Adiponectin $(\mu \mathrm{g} / \mathrm{mL})$ & $4.68 \pm 3.98$ & $3.91 \pm 2.21$ & 0.741 \\
\hline Leptin (ng/mL) & $2.11 \pm 1.73$ & $2.81 \pm 2.38$ & 0.061 \\
\hline Log DPP-4 concentration (ng/mL) & $2.71 \pm 0.11$ & $2.72 \pm 0.09$ & 0.592 \\
\hline Fatty liver & $30(39.0 \%)$ & $25(65.8 \%)$ & 0.007 \\
\hline
\end{tabular}

Values are normal distribution and are presented as mean \pm standard deviation (SD) or number (\%).

*Student's t-test or chi-square test or Mann-Whitney test.

MHO, metabolically healthy obese; MUHO, metabolically unhealthy obese; HDL, high-density lipoprotein; LDL, low density lipoprotein; HOMA-IR, homeostasis model assessment of insulin resistance; DPP-4, dipeptidyl peptidase-4.

centration was negatively correlated with body fat percentage and positively correlated with lean body mass. According to Durinx et al. $^{20}$, serum DPP-4 concentration reflects more than 90\% of DPP-4 activity. Lamers et al. ${ }^{14}$ have also observed an association between DPP-4 activity and serum DPP-4 concentration and higher DPP-4 activity in the obese group compared with the non-obese group. These findings suggest that both DPP-4 concentration and DPP-4 activity may be associated with obesity. However, on the other hand, Kim et al. ${ }^{21}$ reported no association between BMI and DPP4 activity in obese patients. Their study only included menopausal women, and the patients in the non-obese group were nearly overweight, with a mean BMI of $22.4 \pm 1.5 \mathrm{~kg} / \mathrm{m}^{2}$. The results of the present study in which serum DPP-4 concentration was positively correlated with BMI and a significant difference in serum DPP-4 concentration was found between the normal weight and obese groups, while no significant difference was observed between the overweight and obese groups, consistent with the results of previous studies. However, unlike our expectations, serum DPP-4 concentration was negatively correlated with body fat percentage and positively correlated with lean body fat. Neidert et al. ${ }^{22}$ reported a negative correlation between DPP-4 activity and body fat percentage and gynoid fat and a positive correlation between DPP-4 activity and lean body mass, suggesting that the level of DPP-4 activity may change according to the body composition rather than the degree of obesity. The distribution of adipokines varies depending on the adipose tissue depots, and visceral adipose tissue is reported to have a large distribution of DPP- $4 .^{23}$ In a study by Lamers et al. ${ }^{14}$, higher levels of DPP-4 were secreted from visceral fat than subcutaneous fat. In the present study, serum DPP-4 concentration increased as the degree of obesity, waist circumference, and WHR increased. Therefore, as has already been suggested in previous studies, abdominal fat may be associated with DPP-4. It has recently 
been reported that symptoms of metabolic syndrome differ depending on fat distribution. ${ }^{24,25}$ Glutofemoral fat is known to play a protective role that contributes to healthy metabolism unlike abdominal fat. ${ }^{24,25}$ However, it is not possible to determine whether the body fat percentage reduction signifies a reduction in the amount of gynoid fat as was the case in a study by Neidert et al. ${ }^{22}$, and a further investigation is needed in this regard. DPP-4 is expressed in various tissues, and its role as a myokine has been suggested after the discovery that myotubes release DPP- $4 .{ }^{26,27}$ While the secretion of DPP-4 by muscles was found to increase due to the effects of whey proteins and muscle contraction in cell and animal experiments, the same was not observed in human experiments. ${ }^{27}$ Little has been reported about the association between DPP-4 and muscle in clinical research. In the multivariate analysis performed in this study, an association between DPP-4 and muscle was consistently observed, and thus, additional research on the role of DPP-4 in muscle is necessary. In addition, different results can be observed within an obese population according to obesity phenotype. Numerous studies have recently reported that obesity can be further classified into metabolically health obesity, metabolically unhealthy obesity, and so on depending on fat distribution. ${ }^{28,29}$ In a study by Turker et al. ${ }^{29}$, blood pressure, BMI, triglyceride, LDL, and fasting glucose levels, and HOMA-IR were higher in the MUHO group than in the MHO group. They reported that while the risk for cardiovascular diseases in the MHO group was not as high as that in the MUHO group, it was higher than that in the normal weight group..$^{29}$ In this study, similar results regarding metabolic factors were observed, and the proportion of patients with fatty liver was higher in the MUHO group than in the MHO group. However, while a significant difference in DPP-4 concentration was found between the normal weight and obese groups, no significant difference was found between the $\mathrm{MHO}$ and $\mathrm{MUHO}$ groups. Since the MUHO group had a relatively small number of subjects compared to the MHO group, further investigation involving a greater number of patients is needed.

Obesity is a risk factor for renal and cardiovascular diseases. ${ }^{30,31}$ Recent studies have reported an association of DPP-4 in blood with cardiac diseases and kidney damage that may or may not be related to GLP-1. Inhibition of DPP-4 has been reported to have cardio-protective and renal-protective effects. ${ }^{32,33}$ In the present study, a positive correlation was found between serum DPP-4 concentration and creatinine levels. This finding may be associated with the reports that inhibition of DPP-4 inhibits kidney damage.

In summary, serum DPP-4 concentration was significantly higher among Korean participants who were obese than those of normal weight and associated with various obesity-related factors. However, since this study only included patients from a single institution, a large-scale research study must be conducted in the future. Furthermore, to assess the potential of serum DPP-4 concentration as a predictor of obesity and obesity-related metabolic syndrome, serum DPP-4 concentration and activity must be compared. Because bioelectrical impedance analysis of an association between serum DPP-4 concentration and body composition has limitations, further research on the mechanism and role of DPP-4 is required.

\section{CONFLICTS OF INTEREST}

The authors declare no conflict of interest.

\section{ACKNOWLEDGMENTS}

The research was supported by the Bisa Research Grant of Keimyung University in 2012 (20120074).

\section{REFERENCES}

1. Reaven G, Abbasi F, McLaughlin T. Obesity, insulin resistance, and cardiovascular disease. Recent Prog Horm Res 2004;59: 207-23.

2. World Health Organization. Fact sheet. Obesity and overweight: Updated June 2016. [accessed 2016 Sep]; Available from: URL: http://www.who.int/mediacentre/factsheets/ fs $311 /$ en/

3. Ogden CL, Carroll MD, Kit BK, Flegal KM. Prevalence of obesity in the United States, 2009-2010. NCHS Data Brief 2012:1-8

4. Korea Centers for Disease Control and Prevention. Korea Health Statistics 2012: Korea National Health and Nutrition Examination Survey (KNHANES V-3). Seoul: Korea Centers for Disease Control and Prevention; 2012. 
5. Kershaw EE, Flier JS. Adipose tissue as an endocrine organ. J Clin Endocrinol Metab 2004;89:2548-56.

6. Zhang Y, Proenca R, Maffei M, Barone M, Leopold L, Friedman JM. Positional cloning of the mouse obese gene and its human homologue. Nature 1994;372:425-32.

7. Mentlein R. Dipeptidyl-peptidase IV (CD26)--role in the inactivation of regulatory peptides. Regul Pept 1999;85:9-24.

8. Deacon CF, Plamboeck A, Møller S, Holst JJ. GLP-1-(9-36) amide reduces blood glucose in anesthetized pigs by a mechanism that does not involve insulin secretion. Am J Physiol Endocrinol Metab 2002;282:E873-9.

9. Drucker DJ, Nauck MA. The incretin system: glucagon-like peptide-1 receptor agonists and dipeptidyl peptidase- 4 inhibitors in type 2 diabetes. Lancet 2006;368:1696-705.

10.Zhong J, Rao X, Rajagopalan S. An emerging role of dipeptidyl peptidase 4 (DPP4) beyond glucose control: potential implications in cardiovascular disease. Atherosclerosis 2013;226: 305-14.

11. Firneisz G, Varga T, Lengyel G, Fehér J, Ghyczy D, Wichmann $B$, et al. Serum dipeptidyl peptidase-4 activity in insulin resistant patients with non-alcoholic fatty liver disease: a novel liver disease biomarker. PLoS One 2010;5:e12226.

12. Holst JJ, Deacon CF. Inhibition of the activity of dipeptidylpeptidase IV as a treatment for type 2 diabetes. Diabetes 1998; 47:1663-70.

13. Kirino Y, Sei M, Kawazoe K, Minakuchi K, Sato Y. Plasma dipeptidyl peptidase 4 activity correlates with body mass index and the plasma adiponectin concentration in healthy young people. Endocr J 2012;59:949-53.

14. Lamers D, Famulla S, Wronkowitz N, Hartwig S, Lehr S, Ouwens DM, et al. Dipeptidyl peptidase 4 is a novel adipokine potentially linking obesity to the metabolic syndrome. Diabetes 2011;60:1917-25.

15. Kim MK, Lee WY, Kang JH, Kang JH, Kim BT, Kim SM, et al. 2014 clinical practice guidelines for overweight and obesity in Korea. Endocrinol Metab (Seoul) 2014;29:405-9.

16. Wildman RP, Muntner P, Reynolds K, McGinn AP, Rajpathak $\mathrm{S}$, Wylie-Rosett J, et al. The obese without cardiometabolic risk factor clustering and the normal weight with cardiometabolic risk factor clustering: prevalence and correlates of 2 phe- notypes among the US population (NHANES 1999-2004). Arch Intern Med 2008;168:1617-24.

17. Abbott CA, Yu DM, Woollatt E, Sutherland GR, McCaughan GW, Gorrell MD. Cloning, expression and chromosomal localization of a novel human dipeptidyl peptidase (DPP) IV homolog, DPP8. Eur J Biochem 2000;267:6140-50.

18. Yazbeck R, Howarth GS, Abbott CA. Dipeptidyl peptidase inhibitors, an emerging drug class for inflammatory disease? Trends Pharmacol Sci 2009;30:600-7.

19. Williams KH, Vieira De Ribeiro AJ, Prakoso E, Veillard AS, Shackel NA, Brooks B, et al. Circulating dipeptidyl peptidase-4 activity correlates with measures of hepatocyte apoptosis and fibrosis in non-alcoholic fatty liver disease in type 2 diabetes mellitus and obesity: a dual cohort cross-sectional study. J Diabetes 2015;7:809-19.

20. Durinx C, Lambeir AM, Bosmans E, Falmagne JB, Berghmans R, Haemers A, et al. Molecular characterization of dipeptidyl peptidase activity in serum: soluble CD26/dipeptidyl peptidase IV is responsible for the release of X-Pro dipeptides. Eur J Biochem 2000;267:5608-13.

21. Kim SW, Cho EH. High levels of serum DPP-4 activity are associated with low bone mineral density in obese postmenopausal women. Endocrinol Metab (Seoul) 2016;31:93-9.

22. Neidert LE, Wainright KS, Zheng C, Babu JR, Kluess HA. Plasma dipeptidyl peptidase IV activity and measures of body composition in apparently healthy people. Heliyon 2016;2: e00097.

23. Svensson H, Odén B, Edén S, Lönn M. Adiponectin, chemerin, cytokines, and dipeptidyl peptidase 4 are released from human adipose tissue in a depot-dependent manner: an in vitro system including human serum albumin. BMC Endocr Disord 2014;14:7.

24. Manolopoulos KN, Karpe F, Frayn KN. Gluteofemoral body fat as a determinant of metabolic health. Int J Obes (Lond) 2010;34:949-59.

25. Karpe F, Pinnick KE. Biology of upper-body and lower-body adipose tissue--link to whole-body phenotypes. Nat Rev Endocrinol 2015;11:90-100.

26. Raschke S, Eckardt K, Bjørklund Holven K, Jensen J, Eckel J. Identification and validation of novel contraction-regulated 
myokines released from primary human skeletal muscle cells. PLoS One 2013;8:e62008.

27. Neidert LE, Mobley CB, Kephart WC, Roberts MD, Kluess HA. The serine protease, dipeptidyl peptidase IV as a myokine: dietary protein and exercise mimetics as a stimulus for transcription and release. Physiol Rep 2016;4:e12827.

28. Lee TH, Jeon WS, Han KJ, Lee SY, Kim NH, Chae HB, et al. Comparison of serum adipocytokine levels according to metabolic health and obesity status. Endocrinol Metab (Seoul) 2015; 30:185-94.

29. Turker Y, Baltaci D, Turker Y, Ozturk S, Iliev D, Sariguzel YC, et al. Comparisons of clinical and inflammatory parameters of metabolically healthy and unhealthy obese with healthy lean body individuals in Turkish adults. Acta Medica Mediterranea
2015;31:201.

30. Lavie CJ, Milani RV. Obesity and cardiovascular disease: the hippocrates paradox? J Am Coll Cardiol 2003;42:677-9.

31. Ejerblad E, Fored CM, Lindblad P, Fryzek J, McLaughlin JK, Nyrén O. Obesity and risk for chronic renal failure. J Am Soc Nephrol 2006;17:1695-702.

32. Alam MA, Chowdhury MRH, Jain P, Sagor MAT, Reza HM. DPP-4 inhibitor sitagliptin prevents inflammation and oxidative stress of heart and kidney in two kidney and one clip (2K1C) rats. Diabetol Metab Syndr 2015;7:107.

33. Panchapakesan U, Pollock C. The role of dipeptidyl peptidase -4 inhibitors in diabetic kidney disease. Front Immunol 2015; 6:443. 